\title{
EL CICLISMO COMO VECTOR DE DESARROLLO TERRITORIAL
}

\author{
Fermín Rodríguez Gutiérrez \\ Departamento de Geografía, CeCodet \\ Universidad de Oviedo \\ farragut@uniovi.es
}

\section{RESUMEN}

Se aborda el potencial del ciclismo como práctica deportiva de carácter específicamente territorial, totalmente determinado por la geografía, lo que hace de él un objeto de atención por parte de la disciplina, con el fin de conocer su papel en determinados países y la capacidad de estos para utilizarlo como vector de desarrollo territorial. Se da cuenta de una estrategia de especialización inteligente para concretar su expansión en un territorio de escala comarcal y se expone una metodología para crear una máquina-herramienta territorial llamada Anillo Ciclista, que concreta la aportación del ciclismo a una estrategia de desarrollo y a llenar de contenido una marca territorial, relacionando un territorio con el paisaje, el deporte, la actividad industriosa, la especialización turística, la experiencia segura y el esfuerzo controlado.

Palabras clave: ciclismo, Anillo Ciclista, economía del ciclismo, movilidad sostenible.

\section{ABSTRACT}

The potential of cycling as a sport is addressed specifically from the territorial point of view, totally determined by geography, which should make it as an object of attention from this discipline, in order to assess its role in certain countries and the ability of these to use it as a vector of territorial development. A smart strategy is developed to define its expansion in a region and a methodology is showed to create a territorial machine tool called

Fecha de recepción: abril 2014.

Fecha de aceptación: enero 2015. 
«Cyclist Ring» embodying the contribution of cycling to a development strategy and to give substance to a territorial brand, linking a particular territory, landscape, sport, industrious activity, tourism expertise, experience and controlled effort.

Keywords: cycling, Cycling Ring, economy biking, road cycling, sustainable mobility.

\section{EL CICLISMO UN DEPORTE EN EXPANSIÓN DETERMINADO POR LA GEOGRAFÍA}

El ciclismo es una práctica deportiva popular. Millones de personas utilizan la bicicleta como vehículo eficaz para su movilidad, transporte, ocio y deporte en todo el mundo. En los países ricos, a medida que el trabajo ha dejado de tener un componente físico, la bicicleta vuelve a generalizarse para conectar a las personas con el esfuerzo físico de fondo, para el que la especie está programada desde sus orígenes (Diamond, 2013).

El ciclismo es un factor de bienestar personal y calidad de vida, constituyéndo su práctica un indicador de excelencia territorial que, al tener una esencial dimensión geográfica, exige poner en juego, junto al atractivo paisajístico de las rutas, garantías en la seguridad de las mismas. En el entorno de las ciudades facilita la movilidad de la población en los desplazamientos cortos, lo que mejora el hábitat urbano, la calidad de vida y optimiza el consumo energético. En una estrategia de redensificación de las ciudades para hacerlas más austeras y controlar sus procesos de difusión, la bicicleta es uno de los complementos imprescindibles para garantizar una movilidad eficiente ${ }^{1}$. En un entorno económico donde la producción manufacturera se encuentra sometida a fuertes presiones competitivas, es preciso explotar nuevas fuentes de riqueza que aprovechen todas las ventajas competitivas del país, especialmente en los territorios de base rural, donde la actividad tradicional se ha degradado, pero siguen perviviendo factores que los hacen atractivos para nuevas actividades, como las deportivas, que pueden poner en valor capacidades no utilizadas por el anterior sistema de producción sobre-energético, aunque si generadas por él, y que hoy dejan de tener la categoría de subproductos para constituirse en capitales intangibles de relación, sobre los cuales se puede edificar una nueva funcionalidad, adaptada a los requerimientos del estado actual de civilización, donde el trabajo no es físico y crecen nuevos sectores de actividad industriosa.

La bicicleta ha estado junto a la humanidad desde hace poco más de un siglo como un medio de transporte que facilita la movilidad personal de manera muy eficiente. Como deporte se refugió en Europa y en la estabilidad de ciertos grandes estados civilizados que ofrecían al mundo las bellezas de paisaje y la diversidad de su territorio, como la arena donde probar el valor de sus esforzados jóvenes. Hoy el ciclismo se adapta a espacios sorprendentes en los cinco continentes, y en los países de Europa adquiere una gran importancia en todos los sentidos, debido al incremento de quienes lo practican con frecuencia y regularidad, a la expansión de las vías ciclables en las ciudades y a la reutilización de vías públicas en áreas rurales, y todo ello para completar rutas de decenas de kilómetros.

1 Esta es una cuestión debatida en el Expert Group Meeting celebrado en Zapopan (México) en octubre de 2014 organizada por ONU-Hábitat y esa municipalidad. 
La relevancia y dimensiones del fenómeno son puestas de manifiesto en estudios como el que Grous, A. (2012) dedica a evaluar, «desde un enfoque holístico» el ciclismo en el Reino Unido, si bien se fija especialmente en la perspectiva que él denomina «economía del ciclismo», cuya aportación a la nacional la estima en «2,9 billones de libras esterlinas por año con una perspectiva de crecimiento fuerte y sostenido a largo término».

Hay países, como Asturias, que cuentan con recursos intangibles asociados a la mítica del ciclismo (tradición, afición, montaña y, en ella, cimas simbólicas), paisajes de elevada calidad, climatología benigna y aprovechable en todas las estaciones, infraestructuras viales de traza y uso adecuadas a la escala ciclista, una ocupación del territorio a partir de villas de alta calidad urbana y una dotación de equipamientos hosteleros y hoteleros que podrían atender las necesidades específicas de una demanda exterior de escala mundial, que busca una práctica segura, en escenarios significativos y bien dotados. Sin embargo, el ciclismo como producto turístico no es un componente explotado en éste y en otros países con potencial de crecimiento en el sector. Es cierto que existen comisiones parlamentarias en las Cortes españolas para estudiar la práctica del ciclismo y proponer medidas para mejorar su ejercicio en condiciones de seguridad, pero no se trata del enfoque integral que vemos reflejado en otros parlamentos, como el caso, de nuevo, del Reino Unido donde una comisión de comunes y lores ha realizado un exhaustivo informe, con numerosas recomendaciones sobre las condiciones del ciclismo en el Reino Unido: Report from the 'Get Britain Cycling' APPCG Inquiry (2012). Este esfuerzo concertado para elevar al ciclismo a política de Estado está dando sus frutos en diversos niveles, como producto de una estrategia inteligente encaminada a hacer del Reino Unido un territorio ciclista.

Para España son escasas las referencias a su control estadístico y análisis económico, y las que hay son relativamente recientes (Rodríguez C., 2014, 2015); esto determina que en informes como los citados para el Reino Unido, donde se establecen comparaciones sobre datos correspondientes a varios países, no aparezcan datos españoles, por lo que el asunto resulta un arcano que dificulta su seguimiento como actividad económicamente organizada. A despejar este vacío contribuye el libro recientemente editado por la Fundación de los Ferrocarriles Españoles y la Universidad de Sevilla (2015) en el que se valoran algunas de las dimensiones del cicloturismo en Europa y en España, obtenidas, las referidas al impacto económico, de uno de los mayores expertos en la materia (Weston, 2012) quien determina en 1.620 millones de euros al año el retorno económico directamente derivado de las pernoctaciones de cicloturistas en España en 2011, lo que lo sitúa en el décimo lugar de los países europeos, inmediatamente detrás de Hungría y a mucha distancia de Alemania, donde las gastos vinculados a las pernoctaciones suponen 2.030 millones de euros. Este es un mercado en crecimiento y a la vista de su actual estructuración en España es previsible que la tendencia sea expansiva y mantenida en el tiempo, manifestando un rendimiento superior al turismo general, pues el gasto diario, establecido entre 50 y 70 euros por persona y día es superior al del turista general; con un gasto medio por viaje de siete días establecido entre 400 y 500 euros por cicloturista para 2011. El cambio de tendencia también lo anuncian, a la vez que contribuyen a fijarlo, la presencia en España, y en concreto en Asturias, de marcas industriales de reconocimiento internacional en la producción de bicicletas; los hoteles de alta calidad para ciclo-deportistas; el mundo de la competición, con estrategias de comercialización de producto que van más allá de la mera 
difusión de una marca, el nacimiento de algún nuevo equipo profesional y el renovado interés de los grandes medios de comunicación por los eventos ciclistas, profesionales y populares, de alto nivel.

Se siente la necesidad y se presenta la oportunidad de aprovechar todos estos factores para utilizar al ciclismo como un componente de marcas territoriales, que tengan como objetivo el de que millones de personas aficionadas al ciclismo en todo el mundo asocien la región de referencia, en este caso Asturias, a un destino preferente para la práctica del ciclismo en sus diversas variantes deportivas. A pesar de sus evidentes ventajas comparativas, Asturias está hoy muy lejos de este propósito. Es muy reciente y escasa la oferta turística especializada en el ciclismo, aunque desde 2013 ha aparecido un centro de atracción de primer nivel vinculado a un potente establecimiento hotelero Las Caldas Villa Termal asociado a la red Bikefriendly, marca dirigida a explotar «una nueva línea turística emergente. El cicloturismo nacional e internacional» (Bikefriendly, 2014) como parte de una red europea más amplia de alojamientos amigos de los ciclistas y la bicicleta (Mourek y Kazda, 2012).

Desde el ámbito académico ligado a la geografía existen destacables trabajos relacionados con los deportes de aventura y con su impacto territorial (Lacosta, A.J. 2001) o con el ciclismo como metáfora territorial, precisamente referida a Asturias, que realiza Capellà Miternique (2001), los que ha producido CeCodet de la Universidad de Oviedo o los que se han realizado en el departamento de Geografía de la Universidad de Sevilla. El territorio es objeto de simbolización creciente, como producto diferenciado frente a la homogeneización generalizante. El Giro, el Tour, la Vuelta reiterada, son argumentos para fijar en la memoria colectiva de una comunidad el aprecio por su territorio, su exhibición orgullosa y su pretensión de ser identificado por los otros como país de calidad, lo que queda especialmente claro en las retransmisiones deportivas en ciudades de referencia (París, Londres, Madrid, Barcelona) donde el espectáculo es la propia ciudad, a partir de una esmerada realización televisiva, y la coartada el acontecimiento deportivo que, por reiterado en una gran vuelta, es marcado por la determinación que, en forma de diferencia, ejercen los lugares que singla, entrevistos como paisaje, ya sea urbano, montañoso, costero... y como escenario para dramatizar un espectáculo, en el que adquieren más valor la gesta personal del deportista y la expresión de los símbolos de pertenencia geográfica de los espectadores que la adhesión a un equipo o marca.

Precisamente este carácter ontológico del ciclismo, coherente con su condición de deporte geográfico, hace que las actuaciones sobre él tengan el mismo carácter integrado que los proyectos de desarrollo territorial. El ciclismo es un crisol de capital social y las acciones de mejora sobre él son de amplio espectro de participación, requiriendo de la acción coordinada de las administraciones públicas, de las empresas operadoras y de las entidades sociales amantes del ciclismo, todas orientadas hacia un objetivo territorial fácilmente identificable con el interés general y difícilmente deslocalizable, por lo que puede ser componente básico de una marca territorial, como el caso de la que aquí proponemos: Asturias. Paraíso ciclista.

Existen inversores particulares que apuestan por la actividad en este sector, y hay un relativo interés público, en razón de las entrevistas capacidades territoriales que a estos efectos presentan ciertas regiones. En una fase inicial de una estrategia de desarrollo territorial basada en el ciclismo creemos que se necesita una visión que identifique y mejore las piezas críticas indispensables para poner en marcha los distintos componentes de una 
operación integrada que, finalmente, en forma de múltiples productos, respirará la atmósfera de excelencia creada por la marca; en este caso Asturias. Paraíso ciclista y generará externalidades para ayudar a las empresas que convergen directa o indirectamente en la marca.

Hoy las formas de especialización del trabajo, los sistemas económicos de intermediación y el ambiente industrial, favorecen las formas de cooperación entre empresas, que encuentran en el territorio el factor último que propicia la sinergia. Naturalmente existen también elementos sociológicos que pueden propiciar esta forma de desarrollo económico. En algunas regiones, el tipo de sinergia entre organizaciones productivas y territorio regional es fruto de una larga historia acompañada de una fuerte acción institucional y política; en otros casos, esta interacción es el fruto de una acción voluntaria apoyada por el gobierno. Creemos que esta segunda vía es la más adecuada para lanzar esta estrategia.

Planteamos aquí la generación de un proyecto de desarrollo vinculado al ciclismo y, por extensión, a los deportes de aventura; todos con una importante determinación geográfica. Lo hacemos basándonos en los métodos de la excelencia territorial, que fomentan la visión ampliamente compartida sobre una estrategia, para facilitar la acción concertada de los actores significativos en la creación de la marca Asturias. Paraíso ciclista; identificando los sectores y factores-clave donde actuar; facilitando la creación de una cadena productiva y la generación de nuevos proyectos empresariales y territoriales sobre esa nueva actividad. Una de las piezas componentes la hemos llamado Anillo Ciclista; tiene como finalidad ofrecer una plataforma para la práctica del ciclismo en condiciones de seguridad y con un nivel de excelencia, tanto en la cualidad de la ruta como en los servicios que asociados a ella puede obtener el ciclista y que están vinculados a las capacidades del territorio, ofrecidos a clientes externos que son atraídos por esta especialización del territorio y a usuarios internos que los demandan para su bienestar. El Anillo Ciclista, cerrado y diverso, es el soporte de otros desarrollos que vinculan a la hotelería y a la hostelería, al ocio, a la industria y los servicios vinculados al deporte. Aquí se perfila y completa el esquema de una estrategia general aplicada a un territorio concreto (Rodríguez Gutiérrez, 2006) ampliando algunos aspectos conceptuales y metodológicos y ahondando en las peculiaridades de la base física del Anillo Ciclista, asunto de interés para diferentes disciplinas focalizadas sobre el paisaje (Centro de Estudios Paisaje y Territorio, 2010).

La concepción del proyecto como Anillo es una importante cuestión, conceptual, metodológica y operativamente. Por un lado, su concepción cerrada es imprescindible para evitar las rupturas y discontinuidades que hacen perder calidad y seguridad, originando trastornos y confusión. Por otra, el origen del proyecto como acción voluntaria hace que el ámbito territorial sea el administrativo de sus promotores; pero esto no debe hacer olvidar que en la correspondiente divisoria administrativa no finalizan las carreteras de interés, lo que hace que el proyecto pueda ser extendido a las unidades administrativas vecinas, manteniendo la coherencia necesaria para asegurar la marca. Especialmente interesante parece la conexión con la vertiente leonesa, que compone la misma región cumbreña de la cordillera, en la que, si bien, sus puertos son de menor longitud, debido a la mayor altitud de la superficie de partida, evidentemente alcanzan la misma cota. Esto, añadido al interés paisajístico de las rutas y al carácter «congelado» en el tiempo de algunas vías, como, por ejemplo, las que ascienden a los puertos de Piedrafita o Vegarada, son factores que multiplican el interés de su conexión al Anillo, pues no hay una frontera sino una región compartida. 


\section{LA DETERMINACIÓN DE LAS CAPACIDADES CICLISTAS DE UN TERRITORIO. LA MON- TAÑA CENTRAL DE ASTURIAS}

El territorio denominado Montaña Central de Asturias, está formado por los concejos de Aller, Lena, Mieres, Morcín, Riosa y Ribera de Arriba, se sitúa en el centro meridional del Principado de Asturias, ocupa una extensión equivalente al $9 \%$ del total de la región, y en él residen 83.000 habitantes, un 7,8\% del total. Los atributos de la comarca, tanto físicos como sociales, permiten considerarla como territorio ciclista, y avalan la propuesta de proyectar una estrategia de futuro donde el ciclismo y la actividad generada en torno a él puedan convertirse en uno de los pilares de desarrollo territorial.

El modelado de la Montaña Central Asturiana, resultado de la acción erosiva del río Caudal y sus afluentes, ha sido condicionado por la cercanía de los altos relieves de la divisoria cantábrica al mar. Es, además, en los concejos de la Montaña Central donde se produce el máximo descenso altitudinal (entre 2.467 y $220 \mathrm{~m}$./a).

Este dato, y la marcada especialización litológica, determinan una desigual reacción ante la erosión, ofreciendo las series plásticas un relieve de formas convexas, suaves y redondeadas, de aspecto compacto, con valles progresivamente más abiertos aguas abajo y fondo aluvial plano, ceñidos por cordales alargados, mientras que las calizas y cuarcitas, mucho más competentes, dan lugar a paisajes en los que predominan las formas agudas,

Figura 1

LOS CONCEJOS DE LA MONTAÑA CENTRAL DEASTURIAS Y SU TRAMA DE POBLAMIENTO PRINCIPAL

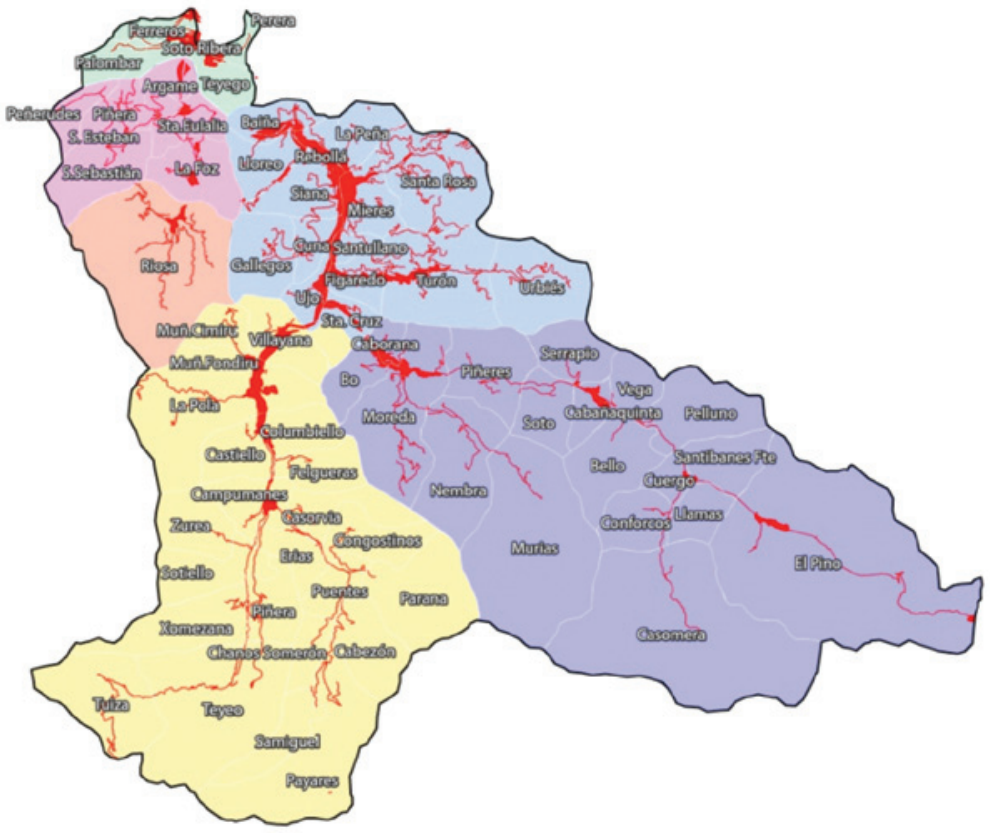

Fuente: elaboración propia. 
violentamente escarpadas, con valles angostos que ven convertidas sus laderas en blancos paredones descarnados o son presididos por oscuras moles cuarcíticas.

Todo ello produce un relieve caracterizado por su accidentación, en el que el terreno se descompone en planos, bastante inclinados, que unen los sucesivos cauces con los puntos culminantes de la respectiva divisoria, siendo escasísimo el desarrollo de las áreas llanas, pues sólo el 3\% del territorio tiene una pendiente inferior al 3\%, lo que coincide con los fondos de valle abiertos por los ríos principales y la superficie cimera, las vegas, de los puertos. A los valles y cordales se añaden unidades de sierra, como las del Aramo y Ubiña, que complican aún más esta compleja geografía, de relieve vigoroso y perfil abrupto, radicalmente de montaña. La sensación que producen estos desplomes desde el fondo del valle en algunos sectores es casi agobiante, despejándose progresivamente el paisaje a medida que se asciende por las vertientes, en las que las sucesivas hombreras y replanos abren las perspectivas y alejan las laderas.

La resultante es un territorio de gran atractivo para la práctica ciclista, por la calidad de su paisaje, pero también por la gran variedad de tipologías de rutas que se pueden recorrer. Segmentos de gran puerto cantábrico, con elevadas pendientes y exigente trazado sinuoso de entre 15 y 30 kms. (La Cubilla, Pajares-Cuitu Negro, L'Angliru, San Isidro, El Gamoniteiru, Coto Bello, o El Rasón. Segmentos de puerto de cordal, sobre la decena de kms. (La Collaona, La Colladiella, El Cordal, San Emiliano, Collau Puerco, San Tirso, Morcín) igualmente exigentes y muy accesibles. Y tramos de valle, caracterizados por seguir el curso de los ríos en áreas con escasa pendiente y en los que incluimos las travesías y vías urbanas.

Figura 2

LA OROGRAFÍA DE LA MONTAÑA CENTRAL DE ASTURIAS

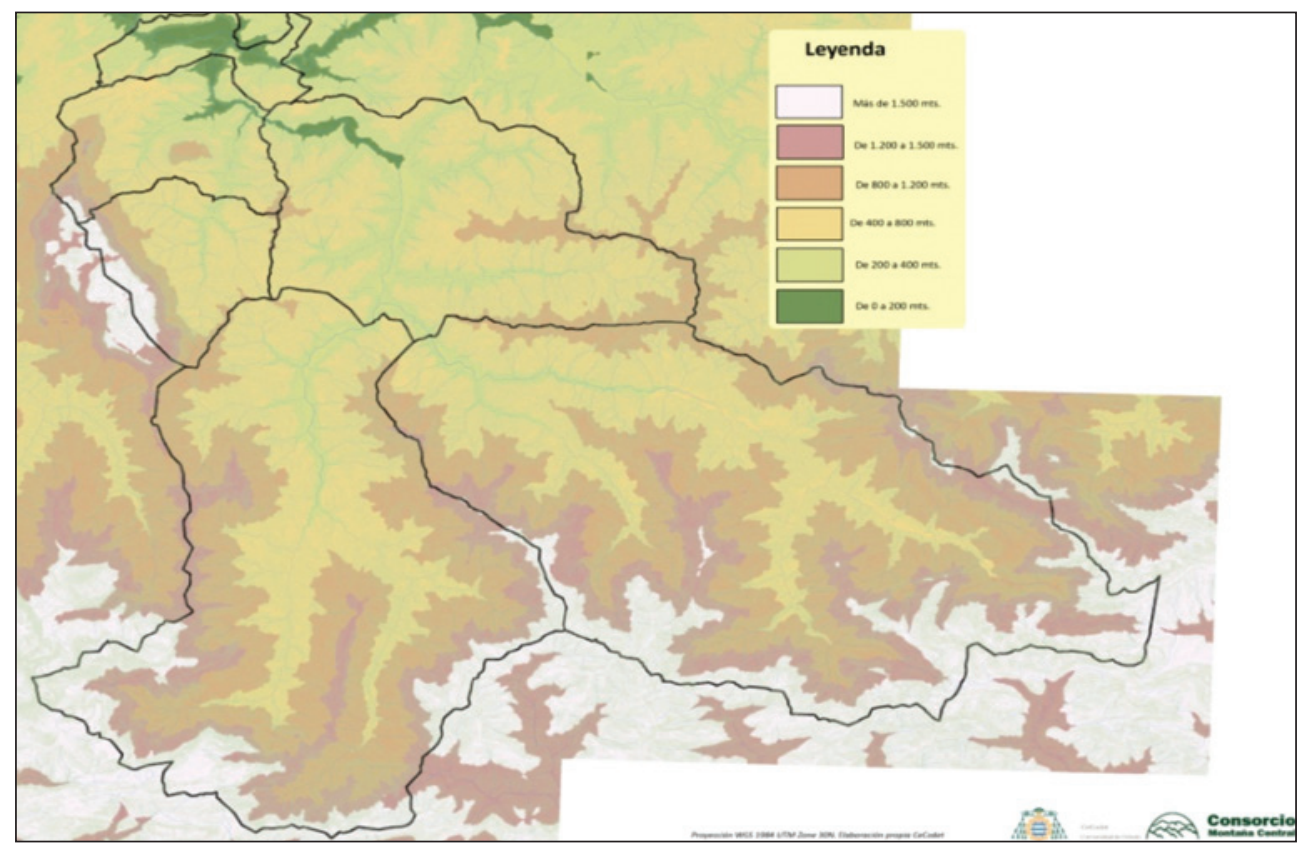

Fuente: elaboración propia. 
El segundo factor que fundamenta la propuesta radica en la tradición ciclista de la Montaña Central. Desde el uso de la bicicleta como medio de transporte a su práctica como deporte desde comienzos del siglo pasado, la bicicleta constituyó uno de los elementos identitarios de la comarca. A ello contribuyeron factores como el elevado grado de urbanización producto de la concentración industrial; su bajo coste de utilización, que hizo que se popularizara entre la población obrera; las escasas posibilidades de ocio y deporte alternativo; la presencia de grandes hitos geográficos convertidos por la radio y la prensa en lugares simbólicos en su dimensión social y deportiva. Todo ello constituyó la base de una práctica y de un espectáculo significativo. De esta manera, ciclismo y sociedad civil han permanecido unidos hasta nuestros días, encontrando expresión de esto en los numerosos clubes organizadores de competiciones y peñas o asociaciones cicloturistas o ciclodeportistas. Además, su calidad de territorio ciclista se ve reflejada en la proyección nacional e internacional de las pruebas que utilizan su territorio y que representan un escaparate para la promoción turística.

Sobre la base del paisaje, de urbanización densa y agreste naturalidad, y de la carretera, como plataforma, símbolo e historia, se forjan los atributos de un territorio ciclista, como es la Montaña Central, que constituye un capital intangible, susceptible de ser puesto en valor para convertirlo en capital relacional; esto es, capaz de generar actividad y dinamismo.

El turismo activo, el de aventura o de naturaleza y el turismo rural pueden constituirse en yacimiento de oportunidades de negocio. Dentro de la perspectiva económica que entiende el ciclismo como plataforma de negocio es importante tener en cuenta la orientación que los sectores de la hostelería y del turismo deben adoptar para cubrir las demandas originadas por los visitantes interesados en este tipo de actividad. La Montaña Central de Asturias es una comarca que no ha participado en el crecimiento del empleo que en Asturias ha experimentado el sector terciario entre 2006 y 2013 (30\%) pues en ella el aumento no alcanza el 5\%, concentrando las escasas empresas de turismo activo en Aller (seis) y Lena (cuatro), concejos en los que radican las estaciones de esquí, a las cuales se ligan los establecimientos de alquiler de material y de organización de actividades de turismo activo. El sector hostelero y hotelero sigue dedicado a satisfacer una demanda tradicional, escasamente abierta al exterior. En 2013 SADEI registraba 29 hoteles, 79 alojamientos de turismo rural, 138 restaurantes y

Cuadro 1

EVOLUCIÓN DEL N DE ESTABLECIMIENTOS TURISTICOS EN LA MONTAÑA CENTRAL DE ASTURIAS (2006-2013)

\begin{tabular}{|c|c|c|c|c|c|c|c|c|c|c|c|c|c|c|c|c|c|c|}
\hline & \multicolumn{3}{|c|}{ Hoteles } & \multicolumn{3}{|c|}{ Pensiones } & \multicolumn{3}{|c|}{ Hot. rurales } & \multicolumn{3}{|c|}{ Casas aldea } & \multicolumn{3}{|c|}{ Apart. rural } & \multicolumn{3}{|c|}{ Restaurantes } \\
\hline & 13 & 06 & V & 13 & 06 & V & 13 & 06 & V & 13 & 06 & V & 13 & 06 & V & 13 & 06 & $\mathbf{V}$ \\
\hline Aller & 8 & 8 & - & 1 & 1 & 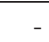 & 2 & 0 & +2 & 17 & 7 & +10 & 8 & 7 & +1 & 30 & 30 & \\
\hline Lena & 7 & 5 & +2 & 3 & 1 & +2 & 2 & 0 & +2 & 12 & 8 & +4 & 7 & 11 & +4 & 29 & 28 & +1 \\
\hline Mieres & 7 & 5 & +2 & 2 & 4 & -2 & 0 & 0 & - & 3 & 7 & -4 & 1 & 2 & -1 & 58 & 45 & +13 \\
\hline Morcín & 0 & 0 & - & 0 & 0 & - & 1 & 1 & - & 11 & 6 & +5 & . & 1 & +1 & 10 & 10 & \\
\hline Ribera & 0 & 0 & - & 0 & 0 & - & 0 & 0 & - & 8 & 7 & +1 & 0 & 0 & - & 6 & 6 & \\
\hline Riosa & 1 & 1 & - & 0 & 0 & - & 1 & 0 & +1 & 1 & 3 & -2 & 3 & 1 & +2 & 5 & 5 & \\
\hline MCA & 23 & 19 & +4 & 6 & 6 & - & 6 & 1 & +5 & 52 & 38 & +14 & 21 & 22 & -1 & 138 & 124 & +14 \\
\hline
\end{tabular}

Fuente: SADEI (2013). 
564 bares. Es evidente que la comarca no es una isla y que en su vecindad se asienta Oviedo y el conjunto metropolitano, fácilmente accesible y que, por lo tanto, debe ser considerado como potencial utilizable. Fijándonos en el interior de la unidad si se percibe un incremento de la oferta turística desde 2006 a 2013, que puede ser calificado de débil, a pesar de las bajas cifras de partida y capaz de crecer notablemente en el futuro.

\section{LOS OBJETIVOS DE UNA ESTRATEGIA DE ESPECIALIZACIÓN TERRITORIAL INTELIGENTE BASADA EN EL CICLISMO}

El fomento del ciclismo en la Montaña Central de Asturias es el objetivo, mediante actuaciones que contribuyen a facilitar su práctica, como una pieza más de la estrategia de reestructuración territorial de la Montaña Central orientada a la excelencia territorial.

Evaluar el capital físico con que se cuenta, a fin de determinar la capacidad del territorio para sostener una oferta relacionada con el ciclismo, ha requerido una metodología específica, que intenta tasar el esfuerzo, el paisaje, la seguridad, el estado de las infraestructuras y las dotaciones hosteleras. Para ello es necesario realizar un inventario de las vías de interés ciclista. También es conveniente evaluar la percepción de todos los participantes. Los más cercanos serán informadores relevantes de aspectos como la seguridad vial, las mejoras en las infraestructuras, la educación vial ... y propondrán acciones concretas que darán un sentido inteligente a la estrategia.

La conciencia de un proyecto vanguardista en una comarca muy pegada a las formas industriales tradicionales explica la lentitud en su implementación y hace considerar que el esfuerzo debe ser mantenido a medio plazo, pues la estrategia necesita vectores estables de operación; siendo importantes la orientación hacia el ciclismo de un gran establecimiento hotelero localizado en la inmediación, como es Las Caldas Villa Termal; la perseverancia en esta línea del CeCodet de la Universidad de Oviedo; la potencia del grupo institucional promotor: el Consorcio para el Desarrollo de la Montaña Central de Asturias, que agrupa a entidades locales y privadas y que es el operador de varios programas de desarrollo como Leader, estando esta propuesta en el centro de la elaborada como «Estrategia territorial de desarrollo rural para el período 2014-2020».

De la implementación del proyecto se seguirán mejoras en las infraestructuras y en la seguridad vial; la creación de carriles-bici en determinadas vías, especialmente en las urbanas; la estructuración documental e informativa de la red ciclista; la integración del sector hostelero en la nueva dinámica, a través de la reorientación de sus negocios hacia esta demanda específica, reforzada con ofertas complementarias: gastronómicas, culturales...; la difusión de las cualidades de la Montaña Central para la práctica ciclista, a través de una campaña de promoción del Anillo Ciclista a escala nacional e internacional dirigida a sectores especializados; y mediante su integración en espacios motores (Ruta de la Plata y Camino de Santiago) a los que se conectan redes empresariales orientadas a la explotación de productos. Todo con una finalidad: contribuir a la ocupación dinámica del territorio, en una comarca cuyo principal rasgo geográfico es su alarmante envejecimiento, lo que implica el vacío territorial y la desvitalización generalizada, pudiendo considerarse el ciclismo como un elemento de adición de valor a las capacidades territoriales detectadas en la misma. 


\section{LA METODOLOGÍA}

El proyecto de crear el Anillo Ciclista de la Montaña Central de Asturias se plantea como concreción de una estrategia de especialización territorial inteligente con una utilidad práctica y tiene muy en cuenta al paisaje. El paisaje es el producto físico amalgamado en el crisol territorial, donde se funden los componentes de la vida social y, en algunos lugares, debido a su originalidad geográfica, se convierte en valor añadido del territorio, y así es percibido por los participantes en él. El artículo trabaja en este campo y con un propósito ejemplar, pues pretende elaborar una metodología para ayudar a cuidar el paisaje de las carreteras, para garantizar un plan de seguridad a los ciclistas, y para contribuir a la actividad industriosa del país, Asturias, ya sea favoreciendo la ocupación dinámica de las áreas rurales en peligro de desactivación funcional como mejorando la movilidad y el bienestar en las áreas urbanas.

Con el propósito de utilizar el potencial de la Montaña Central para la práctica del ciclismo, fue necesario construir una metodología para el análisis de las condiciones de las carreteras (trazado, elementos, seguridad, niveles de dificultad en función de la exigencia para el ciclista) y del paisaje de las mismas. Una metodología innovadora, que aquí se prueba en un lugar concreto, y que puede ser utilizada en otros territorios, como el occidente meridional de Asturias: nodo elevado, enclavado, despoblado, envejecido, marginal, sin funcionalidad económica y de paisaje espectacular, dotado de carreteras que podríamos calificar de park-ways (Rodríguez, F. 2009) y que compone una parte de la Gran Cantábrica, la patria de Finisterre, el hijo de Breogán, refugiado entre breñas inaccesibles, en uno de los lugares de menor accesibilidad de Europa, que tienen el honor de compartir tres comunidades autónomas: Galicia, Castilla y León y Principado de Asturias.

La implementación del Anillo se entiende como un proceso completo, cuyo resultado debe ser aplicable; por eso incluye todas las fases que son propias de la intervención racional sobre una realidad constatable en el territorio: análisis, diagnóstico de situación, modelo que se propone, diseño de un plan de actuación e instrumentos operativos de apoyo. En razón de las dos orientaciones principales del ejercicio ciclista, la que discurre por vías asfaltadas y la que corre por pistas de tierra, diferenciamos dos mallas: la de carretera y la de BTT. Por su originalidad metodológica, por la complejidad de la misma y fundamentalmente por ser la respuesta inicial a las inquietudes planteadas en términos de seguridad y diversificación funcional nos centraremos en la primera malla o componente esencial del Anillo Ciclista.

\section{IV.1. Determinación de la capacidad del territorio, querer y poder dan la medida del potencial}

La fase de trabajo de campo se desarrolla en dos vertientes. Por un lado, se trata de constatar la importancia de la Montaña Central de Asturias como territorio de gran tradición ciclista, para lo cual debíamos realizar un trabajo de campo que documentara la historia del ciclismo en la comarca, identificara sus protagonistas y evidenciara el grado de aceptación y conocimiento que la inteligencia territorial comarcal tiene de la estrategia propuesta. Los instrumentos que utilizamos para conseguirlo estuvieron ligados a la participación y a su expresión en un cuestionario enviado a las organizaciones ciclistas de la comarca, a las entrevistas en profundidad realizadas a informantes-clave relacionados con el mundo del ciclismo y a la recopilación de información documental referida a clubes, 
carreras, deportistas..., además de plantear reuniones de trabajo con formato seminario para tratar estas cuestiones. Los contactos con el sector hostelero fueron realizados también sistemáticamente; si bien el escaso tamaño de éste y la completa ausencia de atención o especializaciòn a y en este sector hicieron que más que un trabajo para obtener información, los seminarios de participación fueran orientados a dar a conocer el potencial del proyecto. Posteriormente, la reorientación hacia el ciclismo de un gran complejo hostelero Las Caldas Villa Termal y su asociación a la red hotelera Friendlybike, dio fortaleza al proyecto, considerado como un elemento de la estrategia de especialización inteligente del programa de desarrollo rural Leader 2014-2020.

El inventario de las carreteras de los concejos de la Montaña Central de Asturias para la práctica ciclista, se obtuvo de la consulta a la Dirección General de Carreteras del Gobierno del Principado de Asturias y a la Delegación Provincial del Ministerio de Fomento. La información aportada se centró, principalmente, en la estructura de las vías y su estado de conservación. Una vez realizado el inventario de carreteras se procedió, de acuerdo con los presupuestos de partida y con la información recogida en los seminarios iniciales y a los informantes-clave, a seleccionar los segmentos componentes del Anillo. Esta base de segmentos viales constituye el conjunto de tramos ciclistas. El mallado de los tramos forma los circuitos y con ellos se integra el Anillo Ciclista de la Montaña Central de Asturias.

\section{IV.2. Leer el territorio: la selección y el estudio de los tramos del Anillo Ciclista}

Los circuitos se segmentaron con el fin de proceder a su estudio exhaustivo. En total se seleccionaron y reconocieron 59 segmentos viales, en las distintas categorías de la red de carreteras, que suman un total de $376 \mathrm{~km}$ a los que se podrán añadir los viales que integran el anillo ciclista de tierra que da $150 \mathrm{~km}$.

Para cada segmento se elaboró una ficha, conteniendo su identificación con indicaciones relativas a su categoría, denominación, accesibilidad, longitud y concejos por los que discurre. Aparecen indicadores básicos que permitirán obtener indicadores sintéticos referidos a seguridad, dificultad y calidad paisajística del tramo. Los básicos hacen referencia a las condiciones del tráfico: intensidad media diaria, presencia de vehículos pesados, velocidad media, «puntos negros»; a las condiciones de la vía: anchura de la plataforma, regularidad de dicha anchura, existencia de arcenes, estado de la calzada, señalización horizontal y vertical, tipo de protecciones, iluminación; desniveles del tramo y determinación de pendientes por segmentos de un kilómetro dentro de cada tramo. A cada ficha se incorporan fotografías que permiten la observación gráfica de los datos aportados por los indicadores y las observaciones complementarias, desde una doble perspectiva: resaltar los elementos positivos de la infraestructura y el paisaje que la enmarca, e indicar los aspectos susceptibles de mejora que contribuyan a orientar acciones, en la propia infraestructura o en su entorno, para el logro de una óptima práctica ciclista. Cada segmento se refleja en una cartografía de escala 1:100.000, en resalte sobre el resto, con información relativa a toponimia, altimetría, cursos fluviales y elementos destacados del relieve, entre otras

Los segmentos del Anillo se unieron para componer tramos, diseñados atendiendo a la variedad del trazado, la diversidad de practicantes a que van destinados, su identidad simbólica, seguridad, dificultad, accesibilidad, etc. 
Figura 3

FICHA DE DIAGNÓSTICO DE UN SEGMENTO CICLABLE

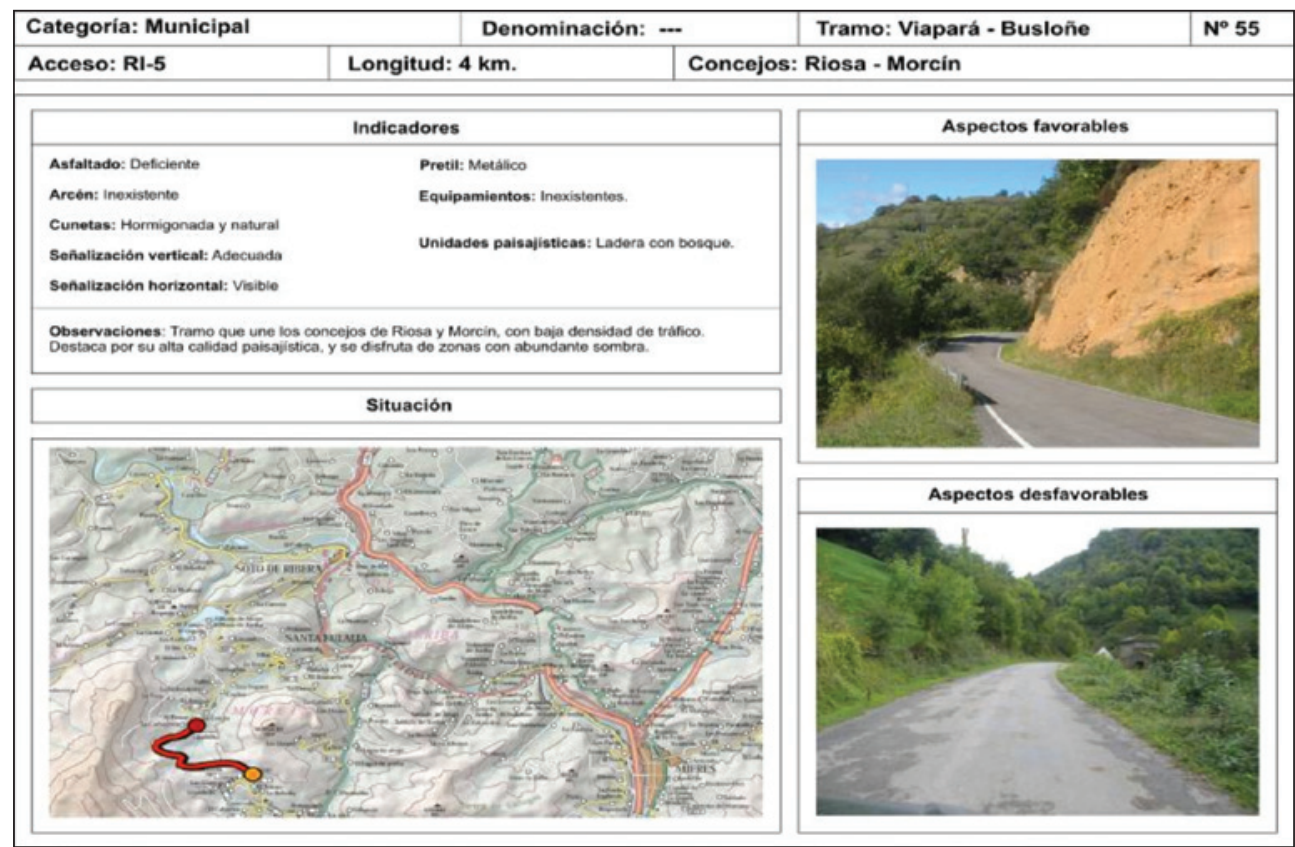

Para cada tramo se establecieron los puntos topográficos de mayor y de menor altitud, definiendo así la diferencia entre cotas, cuyo valor permite una aproximación al nivel de esfuerzo en el tramo.

Se calcularon los desniveles por tramo, expresándolos en porcentajes de desnivel por kilómetro recorrido. La representación de los porcentajes de desnivel se expresa gráficamente sobre los perfiles de cada tramo, con distintos grados de coloración según el porcentaje de desnivel medio obtenido para cada kilómetro.

Se ponderaron las pendientes del tramo. Tomando como variable dependiente el porcentaje de desnivel se establece una ponderación de la pendiente por kilómetro. A menores desniveles los valores de ponderación (pesos aplicables) son también bajos, incrementándose estos pesos a medida que aumentan los desniveles.

Se calcula el Índice de Dificultad Equivalente (IDE) que resulta de la ponderación diferencial de la longitud de los tramos según la pendiente, considerada en segmentos de $1 \mathrm{~km}$. Este indicador proporciona la Dificultad Equivalente del tramo. Cuanto mayor sea la diferencia con su longitud real, mayor será su dificultad equivalente. Este índice permite una valoración global de la dificultad de cada tramo, así como el contraste de la dificultad entre los distintos tramos ciclistas.

Se define el Coeficiente de Esfuerzo (CE) La asignación de coeficientes a los valores obtenidos a partir del Índice de Dificultad Equivalente permite obtener un valor sintético del grado de Esfuerzo para cada tramo ciclista, asignándosele valores entre 1 y 10, correlacionados de forma directa con el ÍDE. 
Se establece la Categoría del Tramo. Un valor del CE requerido para superar un tramo ciclista recibe un adjetivo que lo califica. Las cinco categorías consideradas son: Paseo, Suave, Duro, Difícil y Élite.

\section{IV.3. La elaboración de indicadores sintéticos de cada tramo}

- El indicador de dificultad.

Se refiere a la diferencia altimétrica entre las cotas mínima y máxima del tramo, así como a los porcentajes de desnivel existentes.

\section{Cuadro 2}

PESOS APLICABLES SEGÚN PORCENTAJE DE LA PENDIENTE

\begin{tabular}{|l|c|c|c|c|c|c|c|c|c|c|c|}
\hline Rango de pendientes: & 0 & 1 & 2 & 3 & 4 & 5 & 6 & 7 & 8 & 9 & 10 \\
\hline Peso aplicable: & 1 & 2 & 3 & 4 & 5 & 7 & 10 & 14 & 19 & 25 & 32 \\
\hline & & & & & & & & & & & \\
\hline Rango de pendientes: & 11 & 12 & 13 & 14 & 15 & 16 & 17 & 18 & 19 & 20 & \\
\hline Peso aplicable: & 40 & 49 & 59 & 70 & 82 & 95 & 109 & 124 & 140 & 157 & \\
\hline
\end{tabular}

Fuente: elaboración propia.

Aplicando los pesos asignados a cada tramo ciclista según porcentaje de la pendiente media en un kilómetro, se obtiene el Índice de Dificultad Equivalente para cada tramo, según la fórmula de crecimiento exponencial.

$$
D=\sum_{i}\left(L_{\text {tramo }} \times \text { peso }\right)
$$

Figura 4

REPRESENTACIÓN DEL PESO PONDERADO DE LA PENDIENTE

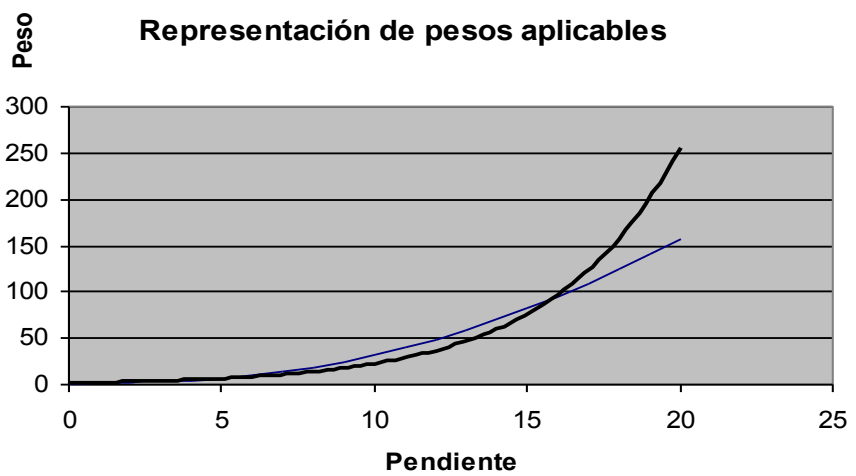

Fuente: elaboración propia. 
Caracterizados los tramos ciclistas de acuerdo al Índice de Dificulta Equivalente, se lleva a cabo una clasificación de los mismos, para lo que se utilizan el Coeficiente de Esfuerzo, con valoraciones de 1 a 10; así como la Categoría del Tramo, considerándolo de Paseo, Suave, Duro, Difícil y Élite.

Cuadro 3

CLASIFICACIÓN DE LOS TRAMOS CICLISTAS

\begin{tabular}{|c|c|c|}
\hline Dificultad equivalente & Coeficiente esfuerzo & Categoría del tramo \\
\hline $11-35$ & 1 & Paseo \\
\hline $36-59$ & 2 & Suave \\
\hline $60-83$ & 3 & \multirow{3}{*}{ Duro } \\
\hline $84-107$ & 4 & \\
\hline $108-131$ & 5 & \\
\hline $132-155$ & 6 & \multirow{4}{*}{ Difícil } \\
\hline $156-179$ & 7 & \\
\hline $180-203$ & 8 & \\
\hline $204-227$ & 9 & \\
\hline $228 y+$ & 10 & Elite \\
\hline
\end{tabular}

Fuente: elaboración propia.

\section{- El indicador de calidad paisajística}

El indicador de calidad paisajística está elaborado a partir de una percepción subjetiva, expresada como valoración realizada por los ciclistas en las encuestas, seminarios y entrevistas. Hace referencia a elementos como amplitud de la cuenca visual, la existencia de vegetación climácica correspondiente a su piso bioclimático, la alteración de la topografía y de la cubierta, la integración de los elementos visuales, la existencia de figuras de protección de espacios naturales, o la armonía o correspondencia con la tipología paisajística por donde discurre el tramo ciclista, su diversidad de paisajes. Su cuantificación se establece entre una calidad baja correspondiente al valor $1 \mathrm{y}$ una calidad alta correspondiente al valor 3 .

\section{- El indicador de seguridad}

El indicador de seguridad hace referencia a los kilómetros de arcén practicable, la anchura media del arcén, la anchura media de la vía, así como al tipo de cierre (metálico, de fábrica, hormigón, madera...), la intensidad del tráfico rodado, la existencia de áreas de riesgo elevado, o al estado del pavimento, expresando de forma sintética la adecuación de los viales para la práctica ciclista. Su cuantificación se establece entre una seguridad baja correspondiente al valor 1 y una seguridad alta correspondiente al valor 3 . 
Figura 5

PERFIL TOPOGRÁFICO DE LA VÍAAL PUERTO DE LA CUBILLA

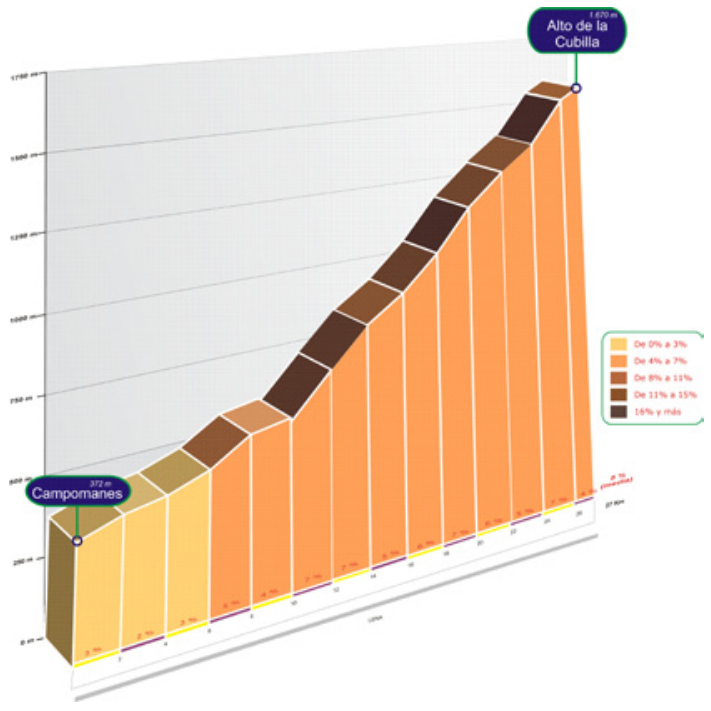

Cuadro 4

EVALUACIÓN DE INDICADORES POR TRAMOS

\begin{tabular}{|c|c|c|c|c|}
\hline $\begin{array}{l}\text { Cuadro general de } \\
\text { tramos ponderados }\end{array}$ & $\begin{array}{l}\text { Distancia } \\
\text { real }\end{array}$ & $\begin{array}{c}\text { Índice de Dificultad } \\
\text { Equivalente }\end{array}$ & $\begin{array}{c}\text { Coeficiente } \\
\text { de } \\
\text { Esfuerzo }\end{array}$ & $\begin{array}{c}\text { Categoría } \\
\text { del } \\
\text { tramo }\end{array}$ \\
\hline \multicolumn{5}{|l|}{ Tramo 1} \\
\hline Cálculo del tramo: Velódromo - Campomanes & 14 & 30 & 1 & Paseo \\
\hline \multicolumn{5}{|l|}{ Tramo 2} \\
\hline Cálculo del tramo: Velódromo - Cabañaquinta & 19 & 37 & 2 & Suave \\
\hline \multicolumn{5}{|l|}{ Tramo 3} \\
\hline Cálculo del tramo: Velódromo - Mieres - Soto Ribera & 20 & 32 & 1 & Paseo \\
\hline \multicolumn{5}{|l|}{ Tramo 4} \\
\hline Cálculo del tramo: Velódromo - La Vega & 20 & 44 & 2 & Suave \\
\hline \multicolumn{5}{|l|}{ Tramo 5} \\
\hline Cálculo del tramo: Velódromo - Turón & 5 & 11 & 1 & Paseo \\
\hline \multicolumn{5}{|l|}{ Tramo 6} \\
\hline Cálculo del tramo: La Vega - L’Angliru & 14 & 515 & 10 & Élite \\
\hline \multicolumn{5}{|l|}{ Tramo 7} \\
\hline Calculo del tramo: Pola de Lena - Alto de La Cobertoria & 10 & 228 & 10 & Élite \\
\hline \multicolumn{5}{|l|}{ Tramo 8} \\
\hline Cálculo del tramo: Moreda - Santibáñez de Murias & 11 & 91 & 4 & Duro \\
\hline \multicolumn{5}{|l|}{ Tramo 9} \\
\hline Cálculo del tramo: Pola de Lena - La Vega & 15 & 73 & 3 & Duro \\
\hline \multicolumn{5}{|l|}{ Tramo 10} \\
\hline Cálculo del tramo: Mieres - Mieres (por El Padrún) & 37 & 185 & 8 & Difícil \\
\hline
\end{tabular}




\begin{tabular}{|c|c|c|c|c|}
\hline $\begin{array}{l}\text { Tramo } 11 \\
\text { Cálculo del tramo: Turón - La Colladiella }\end{array}$ & 12 & 131 & 5 & Duro \\
\hline \multicolumn{5}{|l|}{ Tramo 12} \\
\hline Cálculo del tramo: Cabañaquinta - Alto de La Collaona & 6 & 99 & 4 & Duro \\
\hline \multicolumn{5}{|l|}{ Tramo 13} \\
\hline Cálculo del tramo: Mieres - Sama de Langreo & 14 & 72 & 3 & Duro \\
\hline \multicolumn{5}{|l|}{ Tramo 14} \\
\hline Cálculo del tramo: Soto de Ribera - La Vega (por Morcin) & 24 & 136 & 6 & Difícil \\
\hline \multicolumn{5}{|l|}{ Tramo 15} \\
\hline Cálculo del tramo: Cabañaquinta - Puerto San Isidro & 27 & 219 & 9 & Difícil \\
\hline \multicolumn{5}{|l|}{ Tramo 16} \\
\hline Cálculo del tramo: Campomanes - Estación de Branillín & 21 & 204 & 9 & Difícil \\
\hline \multicolumn{5}{|l|}{ Tramo 17} \\
\hline Cálculo del tramo: Campomanes - Puerto de La Cubilla & 27 & 375 & 10 & Élite \\
\hline \multicolumn{5}{|l|}{ Tramo 18} \\
\hline Cálculo del tramo: Mieres - Santuario los Mártires - Mieres & 14 & 60 & 3 & Duro \\
\hline \multicolumn{5}{|l|}{ Tramo 19} \\
\hline Cálculo del tramo: Santolaya - La Foz & 7 & 42 & 2 & Suave \\
\hline
\end{tabular}

Fuente: Elaboración propia

\section{LA ESCUCHA DE LOS PARTICIPANTES}

Además de un adecuado reconocimiento de las infraestructuras, el proyecto considera las opiniones de las personas y sectores corporativos relacionados con el ciclismo, el turismo y la administración de las carretas y la seguridad del tráfico en ellas, con el fin de obtener una visión ajustada de las capacidades del territorio para concretar esta estrategia y de la voluntad de los participantes para participar en ella. Se obtiene así una panorámica ampliamente compartida sobre los aspectos críticos del proyecto, sobre las potencialidades existentes, y se recogen ideas y proyectos que perfilan la estrategia, así como se identifican las vanguardias portadoras de proyecto.

El grueso de la fase de participación se realizó en paralelo a la redacción del documento. Los participantes se organizaron en tres grupos sectoriales: Grupo 1 de seguridad vial, integrado por representantes de seguridad de los municipios, por responsables y representantes institucionales de tráfico, y por expertos y técnicos relacionados con el diseño, ejecución y mantenimiento de infraestructuras viarias. Grupo 2 de ciclistas, ciclodeportistas y cicloturistas, integrado por representantes de clubes, aficionados y federación. Grupo 3 de integrantes del sector turístico y hostelero, compuesto por propietarios de establecimientos del ramo, así como por instituciones que tienen como fin promocionar la actividad turística.

Cada grupo se reunió en dos ocasiones, en la primera mantuvo su carácter sectorial y la segunda se convocó de forma conjunta. Genéricamente, cada sesión se diferenció en dos partes: una primera en la que el equipo técnico efectuó una presentación de la sesión de trabajo, detallando el procedimiento y los distintos apartados que se iban a tratar, y una segunda, de conversación pautada, en la que se recogen las opiniones de los participantes lanzadas, bien de forma espontánea, o bien teniendo como base los materiales de trabajo entregados. 
El resultado de las mesas de participación fue la elaboración de propuestas concretas, algunas complementarias a las diseñadas por el equipo técnico, otras nuevas.

\section{VI.1. Elaboración de propuestas}

Diferenciamos dos tipos de propuestas: las generales, que dan respuesta a problemas repetidos en los tramos que integran el Anillo Ciclista, y las específicas, que subsanando problemas que afectan a tramos concretos son complementarias a las generales y de especial necesidad, dado que se localizan en puntos de riesgo para el ciclista. Se propusieron acciones en tres tramos muy frecuentados, con el objetivo de incrementar la seguridad de los ciclistas. Consisten en arcenes pintados con la marca vial señalizando vías exclusivas para ciclistas; en la iluminación y el acondicionamiento de arcenes en túneles; la instalación de banda-bionda con protección, línea roja y/o marcadores acústicos en el carril de ascenso a algunos puertos, como marca de separación de los espacios de tránsito para el automóvil y para el ciclista.

\section{VI.1.1. Propuestas generales de accesibilidad y movilidad}

Las de accesibilidad facilitan la entrada al Anillo de usuarios ciclistas que no residen en la comarca y que se dirigen a ella con el propósito de practicar ciclismo. Con éstas se intenta resolver los inconvenientes que encuentran los ciclistas cuando pretenden acceder a determinados tramos. Las de movilidad interna facilitan la continuidad ciclista entre los centros urbanos y el Anillo Ciclista en condiciones de seguridad, así como actúan sobre la ordenación del tráfico en los principales núcleos de población: Mieres, Pola de Lena y Moreda, en los cuales el Anillo tiene carácter de travesía urbana, al que hay que facilitar el acceso desde el resto de la trama urbana y desde las estaciones de transporte, con lo que se está reordenando la movilidad en tales villas, en función de criterios:

A. Dirigidos a facilitar la convivencia entre la bicicleta y el automóvil en la ordenación del tráfico, poniendo especial énfasis en medidas relacionadas con la mejora del transporte colectivo para los usuarios de la bicicleta; la liberación de espacios viarios de vehículos a motor y el acondicionamiento de las estaciones de transporte público para facilitar el uso de la bicicleta

B. Dirigidos a fomentar el uso de la bicicleta en la ciudad mediante la elaboración de planes específicos para aumentar el tráfico ciclista, mediante puntos de alquiler automático de bicicletas; la rehabilitación urbana ligada al uso de la bicicleta, es decir, cualquier actuación urbanística deberá tomar en cuenta las necesidades de espacio que requiere la práctica del ciclismo; la creación de un itinerario urbano seguro y funcional, señalizado y acondicionado y la eliminación de barreras urbanísticas para el uso de la bici.

El diseño y el tratamiento específico de las vías de canalización de ciclistas o colectores de cada uno de los cinco núcleos principales requerirá de actuaciones específicas, garantizando desde cada uno de ellos el acceso, seguro, sencillo y mediante un tramo de categoría Paseo, al punto base del Anillo Ciclista, que se designa como kilómetro 0 y en el que se pretende situar un velódromo. 


\section{VI.1.2. Propuestas de señalización}

La regulación del tráfico de bicicletas establecida en el Código de la Circulación puede ser completada con el propósito de incrementar la seguridad de los ciclistas y de proporcionarles información sobre distintos detalles del recorrido. En la señalización propuesta para el Anillo Ciclista establecemos dos tipos de señales: las de tipo normativo, basadas en el Código de la Circulación y que regulan las determinaciones a las que están sometidos los usuarios de las vías, y las de tipo indicativo, de carácter no vinculante, que proporcionan información a los ciclistas a lo largo de los distintos tramos del Anillo Ciclista.

La señalización normativa es la prescrita por el Reglamento General de Circulación (R.D.1428/2003) y al que todo usuario de una bicicleta o ciclo debe atenerse. La señalización indicativa no se encuentra registrada en ningún reglamento viario, ni en otro tipo de normativa al efecto. Sus indicaciones están realizadas para informar a los usuarios ciclistas sobre diferentes aspectos del Anillo Ciclista, de sus tramos, puertos, áreas de descanso y señalización específica para corredores.

En función de sus contenidos y del carácter informativo, se distinguen las señalizaciones generales, que son las que ni estando recogidas en el Código de Circulación, ni siendo específicas para el Anillo Ciclista de la Montaña Central, están siendo utilizadas para regular el tránsito de los ciclistas.

Las que aquí nos interesan son las específicas del Anillo Ciclista de la Montaña Central de Asturias. Informan al usuario de que se encuentra dentro de él y están situadas en los lugares de entrada y salida, son las de la Fig. 5.
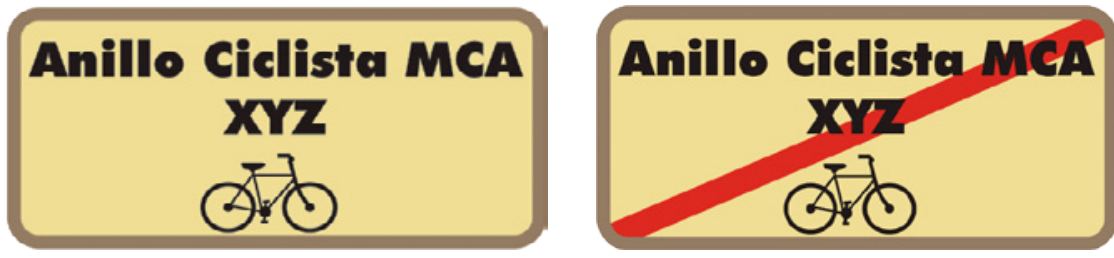

Figura 6

SEÑAL INFORMATIVA ESPECÍFICA PARA TRAMOS DE TRAVESÍA

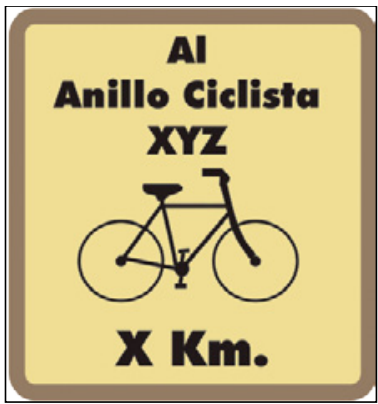




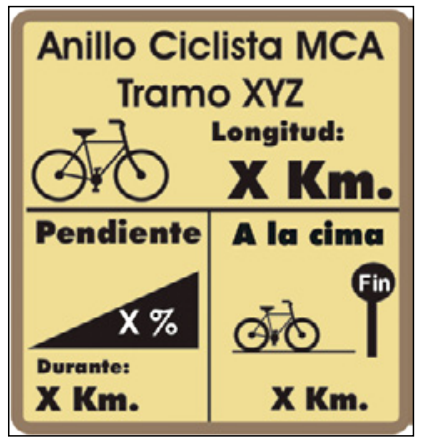

Hay una señal específica que colocada en las travesías, vías de acceso, estaciones, indica la dirección al mismo y la distancia hasta entrar en el tramo

Para los puertos existe una señalización particular, en la que la información se agrupa en tres cuarteles: el primero, contiene información sobre la posición del puerto en el tramo correspondiente; el segundo detalla el porcentaje de la pendiente y la longitud en que ésta se mantiene constante, y el tercero la distancia en kilómetros a la cima.

Figura 8

SEÑAL DE ÁREA DE DESCANSO

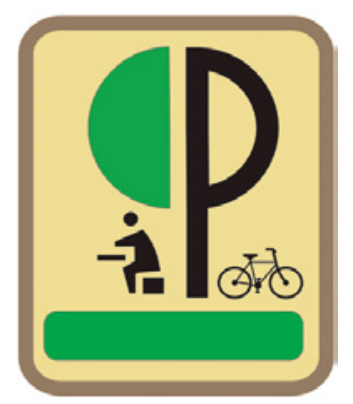

La señalización de área de descanso tiene por fin informar al usuario de la localización de un área apartada del tráfico rodado, preparada para hacer una pausa en el recorrido y ofrecer descanso y avituallamiento a los usuarios. Cumplen características como: la localización anexa a los tramos; tienen disponibilidad de aparcamiento para un número pequeño de vehículos; se distribuyen por la red de carreteras del Anillo en función de las necesidades del ciclista, de la calidad del paisaje divisado y de la oportunidad de aprovechamiento de áreas recreativas ya existentes, cuidando su integración en el paisaje. La señalización afecta exclusivamente a las áreas de descanso del propio Anillo Ciclista, pues el resto de áreas excluidas a la circulación y otros espacios ajenos al tráfico tienen su propia señalización recogida en el Reglamento y Código de Circulación y Seguridad. 


\section{VI.1.3. Propuestas de diversificación económica}

Apoyadas en la evidencia de que la Montaña Central de Asturias tiene la capacidad de poner en marcha una estrategia de especialización inteligente que utilice el ciclismo como factor de desarrollo endógeno. El objetivo es consolidar un sector empresarial vinculado al mundo del ciclismo y ligado a la revitalización de su tejido social, fundamentado en el subsector turístico y hostelero, los servicios a la bicicleta (talleres, tiendas, etc.), y la promoción y comercialización de productos turísticos vinculados a la marca territorial.

El grupo de participación número 3 consideró como claves para la pertinencia de esta estrategia de desarrollo basada en el ciclismo al paisaje, al clima, a las carreteras, a la dotación hotelera y hostelera, a la gastronomía de calidad y a buen precio, a la calidad ambiental, la existencia de puertos míticos y una tradición ciclista reconocida. El acceso al mercado potencial, en cambio, está limitado por una posición excéntrica en la península y por mejorables comunicaciones aéreas y por ferrocarril con el resto de España y Europa, así como por la falta de experiencia en estructurar este tipo de ofertas y el escaso conocimiento sobre la misma de los operadores; en definitiva, la conectividad es cara y débil, el producto no está suficientemente organizado, ni hay una visión que concierte el esfuerzo de públicos y privados para una acción que por su carácter territorial necesita de externalidades más allá de los recintos hoteleros.

La infraestructura hotelera está basada en algunos pequeños hoteles urbanos no especializados y en numerosas casas de aldea diseminadas por la comarca, que necesitan ligarse a una oferta especializada en alguna actividad de amplia demanda.

En el territorio de estudio hay tres grandes estaciones de esquí San Isidro, Fuentes de Invierno y Pajares, con alojamientos dentro de su perímetro y en los núcleos próximos. La inclusión o vecindad al área metropolitana de Asturias (Ciudad Astur) ofrece un mercado interno de tamaño importante que ronda los 900.000 usuarios potenciales.

El grupo de trabajo de turismo demostró interés por la propuesta, a la vez que la nula actividad orientada a esta especialización. Recientemente la instalación en el vecino concejo de Oviedo y en la inmediatez de la Montaña Central de un establecimiento hotelero de alto nivel, asociado a la red Friendlybike desde 2013, como es Las Caldas Villa Termal supone un importante apoyo a esta estrategia, pues la dotación del mismo, su capacidad de irradiación, lo conforma como en un importante vector de interés para apoyar este despliegue en el territorio, hacia el que dirige sus expectativas de rutas ciclistas. La red Friendlybike y sus establecimientos asociados garantizan al cicloturista unos servicios orientados a mejorar su práctica deportiva tanto en las atenciones recibidas en los diversos tipos de hoteles (clásicos, urbanos, experience y resorts) «como en los parajes más bonitos de cada territorio» del que se aprovechan otras capacidades como la gastronómica y, en general, los recursos determinados por la geografía local.

Los hoteles asociados a esta red hacen frente a una demanda en aumento, a la vez que la incentivan; en ella aparecen prestigiosos establecimientos de referencia en España situados en emplazamientos tan significativos como Chiclana-La Barrosa, Gerona o Mallorca, todos los cuales tienen una evidente tradición hostelera y una fuerte conectividad.

Para la diversificación productiva el objetivo es consolidar un sector empresarial vinculado al mundo del ciclismo y del turismo, fundamentado en los siguientes sectores: hotelero 
y hostelero; servicios a la bicicleta; otros servicios relacionados con la práctica ciclista; marca territorial, para un mercado potencial amplio y en expansión.

\section{A. Hostelería}

Hay una tendencia débil de crecimiento en el número de establecimientos hoteleros y hosteleros dentro de la comarca, bien comunicada y accesible desde las vecinas que, por su carácter metropolitano, están bien dotadas. Sobre esta red de establecimientos es posible construir una parte de la estrategia general, destacando como vector propulsor el importante hotel Las Caldas Villa Termal, cuya función puede ser ejemplar y tractora, como referencia de los servicios a prestar: dotación de instalaciones de descanso y recuperación adecuadas para los ciclistas; control médico y de acompañamiento y preparación; mantenimiento de la bicicleta; gastronomía específica, comida saludable. Información, guía y asesoramiento especializado.

\section{B. Servicios a la bicicleta}

La bicicleta es la herramienta del ciclista; su cuidado y equipamiento redundan en su comodidad y seguridad. Las tiendas y de talleres especializados en ciclismo son numerosos en la comarca, apoyados en la numerosa afición y practicantes regulares . Trabajar con ellos en la formación de una red que se conecte a la estrategia general y la amplifique es una necesidad pertinente, pues se trata de un pequeño comercio local acreditado y distribuido regularmente en las villas y otras localidades. En la región se ubica una importante marca de bicicletas que puede actuar como pilar de la estrategia (MMR) con una importante proyección internacional y vinculada a la marca Asturias. Igualmente dos grandes cadenas de distribución deportiva con un importante departamento de ciclismo (Decathlon y Forum) se han mostrado receptivas a la participación y hasta el momento lo han hecho de uno u otro modo.

\section{Marca territorial}

El concepto de Montaña Central Territorio Ciclista se une con la marca Asturias. Paraiso Ciclista. Planteamos la comercialización de productos turísticos complementarios relacionados con los recursos endógenos de la propia comarca (gastronomía saludable ligada al concepto slow food) y asociados al mundo ciclista. Teniendo en cuenta que los fabricantes de bicicletas son productores de marcas y que propiamente no fabrican sus componentes, su estrategia de producto se basa en la comercialización y en la mercadotecnia, y como una de las significativas (MMR) se radica en Asturias hay un interés evidente en recrear una marca compartida, de la que se benefician productos complementarios como vestuario, salud y coach, medicina deportiva, información geográfica para uso hotelero y de empresas de guía ciclista y aventura. Se incide en la búsqueda de sinergias con el «turismo de ski», pues la Montaña Central cuenta con dos de las cuatro estaciones de ski de la cordillera Cantábrica. Ello posibilita la diversificación de la oferta turística sobre las actividades del deporte blanco y del ciclismo, abriendo posibilidades hacia paquetes turísticos que combinen los dos tipos de oferta de cara al turista. También es compatible con el turismo de playa y surf y con el cultural, dada la proximidad a la costa y al conjunto metropolitano de Asturias. 


\section{VI.1.4. Propuestas de difusión}

Las labores de difusión se plantean a través de los operadores correspondientes, ya sean el consorcio comarcal, las instituciones competentes regionales o las empresas y asociaciones interesadas. Se creó un portal digital con la marca registrada «Anillo Ciclista de la Montaña Central de Asturias» para actuar como punto de confluencia de todos los participantes aficionados al ciclismo, agentes turísticos y público en general, con acceso inicial a las direcciones www.mcasturias.org/anillo, o a través del enlace disponible en www.uniovi.es/cecodet. En ella puede encontrarse información detallada de las rutas disponibles, sus características y sus atractivos; y posibilidades que cada una puede ofrecer, contenido relativos a la infraestructura turística y a la oferta hotelera, y una serie de enlaces de interés para los usuarios.

\section{EL MALLADO FÍSICO DEL ANILLO CICLISTA DE LA MONTAÑA CENTRAL DE ASTURIAS}

La propuesta inicial del Anillo Ciclista se organiza a partir de un punto base que, por motivos de centralidad y accesibilidad, se designa como kilómetro 0. Éste se ha localizado en el triángulo Ujo - Mieres - Figaredo. A partir de esta localización se ha estructurado una red de viales que conducirán al diseño de los distintos tramos del Anillo Ciclista.

El velódromo servirá de infraestructura básica y como vertebrador de las dinámicas generadas por el Anillo Ciclista; dotado de pista de rodadura, dependencias complementarias y espacios vinculados a la práctica ciclista. Su ubicación en una posición central estará ligada a su elevado grado de accesibilidad, debiendo situarse por ello en lo que denominamos «Red básica», con un fácil acceso desde los principales núcleos de población de la comarca y desde las principales infraestructuras de transporte, lo que le conferirá una posición óptima como receptor de los principales flujos internos y también extra-comarcales.

La denominada red básica del Anillo Ciclista abarca las vías de conexión del eje principal de comunicación con los núcleos de población más importantes de la comarca, como son los situados en el eje del Caudal y de los otros ríos principales. Los viales que enlazan los núcleos de población situados en dicho eje con el punto base ( $\mathrm{km} 0)$ son carreteras de categoría nacional en su mayor parte, que se caracterizan por un elevado grado de accesibilidad y por trazados de fácil recorrido, en buenas condiciones de seguridad para la práctica ciclista, a la vez que un grado de dificultad bajo.

La red secundaria del Anillo Ciclista consta de las vías de conexión de las cabeceras comarcales con los grandes puertos de la cordillera Cantábrica, de las sierras y cordales interiores, y con otros concejos vecinos u otras localidades del interior de la Montaña Central de Asturias. Se trata de itinerarios que abarcan carreteras de categorías nacional, regional y local; con tramos de amplia longitud y desniveles acusados, lo que les confiere un mayor grado de dificultad. Su trazado discurre en su mayor parte sobre fondos de valle y laderas, con terminaciones en los puertos de montaña más importantes.

Las dos redes carreteras se complementan con la de pistas, que por sus condiciones particulares son aptas para la práctica mediante bicicleta todo terreno y ciclismo mixto. El proyecto global también aborda su implementación, pero por responder a otros requerimientos técnicos específicos no se consideran en este trabajo, si bien los de carácter general son igualmente aplicables. 


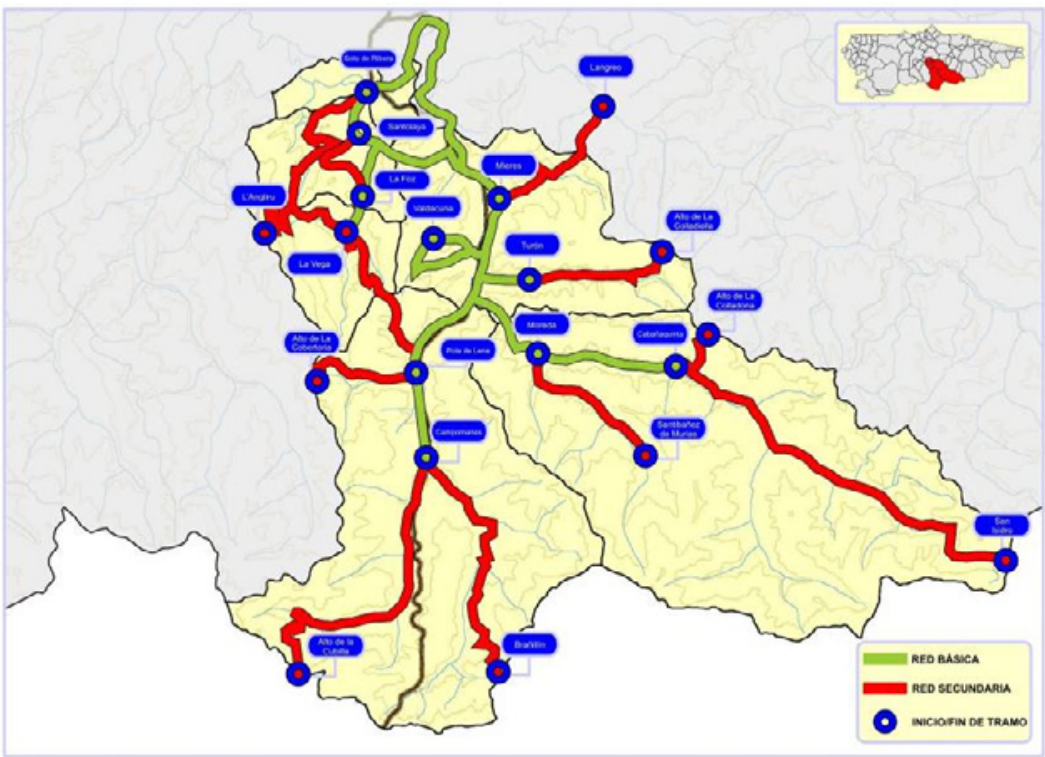

El sistema resultante de la coordinación de la infraestructura del velódromo con las redes básica y secundaria constituye el preliminar Anillo Ciclista de la Montaña Central de Asturias, planteado como una marca reconocible que asegura un plus de calidad, seguridad y disfrute paisajístico al ciclista que se introduzca en ella y al que los establecimientos asociados ofrecen una atención especializada según sus necesidades, ofreciendo a todos la posibilidad de vivir una experiencia de intensas sensaciones en diversos planos, comenzando por el deportivo, al que se acoplan positivamente otros complementarios que permiten participar a sus acompañantes

\section{BIBLIOGRAFÍA}

ALL PARTY PARLIAMENTARY CYCLING GROUP (2012): «Get Britain Cycling' APPCG Inquiry.

BIKEFRIENDLY 2014, en http://www.Bikefriendly.

CAPELLÀ MITERNIQUE, H. (2001): «La vuelta al territorio», en Forma y función del territorio en el nuevo siglo. Actas del XVII Congreso de Geógrafos Españoles. AGE y Universidad de Oviedo, pp. 276-279.

CENTRO DE ESTUDIOS PAISAJE Y TERRITORIO y CONSEJERÍA DE OBRAS PÚBLICAS Y VIVIENDA (2010): Paisaje e infraestructuras, $2^{\circ}$ Congreso 2008, Libro de Actas. Junta de Andalucía, Sevilla.

DIAMOND, J. (2013): El mundo hasta ayer. ¿Qué podemos aprender de las sociedades tradicionales. Debate, Barcelona. 
FUNDACIÓN DE LOS FERROCARRILES ESPAÑOLES y JUNTA DE ANDALUCÍA (2014): El impacto económico del cicloturismo en Europa. Síntesis de los principales estudios realizados.

GROUS, Alexander (2012): The British Cycling economy. Gross cycling product report, LSE, 2012.

LACOSTA ARAGÚÉS, A. J. (2001): «Aproximación al sector del turismo activa y de aventura en España. Implicaciones territoriales y distribución espacial», en Forma y función del territorio en el nuevo siglo. Actas del XVII Congreso de Geógrafos Españoles, AGE y Universidad de Oviedo, pp. 358-364.

MOUREK, D. y KAZDA, P. (2012): Best Practice Guide on Cycle Friendly and other Certifications for Services Along Greenways, AEVV.

RODRÍGUEZ GUTIÉRREZ, C., PÉREZ, L., PUENTE, V. y RODRÍGUEZ, P. (2013): «The determinants of television audience for professional cycling: The case of Spain», Journal of Sports Economics, DOI: 10.1177/1527002512471536.

RODRÍGUEZ GUTIÉRREZ, C. (2014), «Leadership and efficiency in professional cycling», International Journal of Sport Finance, 9 (4).

RODRIGUEZ GUTIÉRREZ, F (2006): Análisis de la influencia del concepto parkways en la concepción de las carreteras construidas en Asturias entre 1900 y 1940. Cehopu.

RODRIGUEZ GUTIÉRREZ, F (2007): El Anillo Ciclista de la Montaña Central de Asturias. Consorcio para el Desarrollo de la Montaña Central de Asturias. Lena.

SADEI (2013): Anuario Estadístico de Asturias 2013.

WESTON, R., DAVIES, N., LUMSDON, L., McGrath, P., PETERS, P., EIJGLAAR, E. y PIKET, P. (2012): The European Cycle Route Network Eurovelo. Retrieved from http:// www.europae.europe.eu/studies. 